報文

\title{
テロマー及び関連化合物の化学及び生物分解性
}

\author{
矢上一夫*・吉田 佳代*・石加美千代*・入佐たまき*・山田 仁穂** \\ $*$ 熊本女子大学生活科学部 ( $干 862$ 熊本市健軍町水洗 2432-1) \\ ** 熊本大学工学部応用化学科 (干 860 熊本市黒髪 2-40-1)
}

\section{Chemical and Biochemical Degradation of the Telomers and Related Compounds}
Kazuo YAGAMI*, Kayo YoSHIDA*, Michiyo ISHIK ${ }^{*}$, Tamaki IRISA*, and Kimiho YAMADA**

* Department of Science of Living Environment, Faculty of Science of Living, Kumamoto Women's University (Mizuarai, Kengun-machi, Kumamoto-shi, ₹862)

** Depertment of Applied Chemistry, Faculty of Engineering, Kumamoto University (Kurokami-machi, Kumamoto-shi, T860)

The chemical and biochemical degradation of telomers from acrylamide ( $\mathrm{Ls}-\mathrm{CONH}_{2}$ ), vinyl pyrrolidone (Ls-VPr), cotelomers of vinyl pyrrolidone and methyl acrylate (Ls-VPr-MA), saponificated telomers of $\mathrm{Ls}_{-}-\mathrm{CONH}_{2}(\mathrm{Ls}-\mathrm{COONa})$, and water soluble polymers and surfactants as controls were studied under aerobic conditions. The above telomers and cotelomers provided excellent detergency when used as detergent builders.

The results showed chemical oxygen demand and biochemical oxygen demand to be closely related. Biodegradability was influenced by the radical group of telomers, the order of biodegradability being follows:carboxyl>pyrrolidone>carbamoyl group. The biodegradability of Ls$\mathrm{VPr}-\mathrm{MA}$ telomers decrease with increase in the degree of saponification of the telomers, even though the number of carboxyl groups of the telomers increased as the process of saponification proceeded. This was considered to result from mutual action between carboxyl and pyrrolidone groups.

The biodegradability of telomers was generally good, exceeding that of poly(acrylamide) and poly(sodium acrylate). The biodegradability of certain telomers was comparable to that of sodium oleate.

\section{1 緒言}

著者らは官能基を異にする種々のテロマーの合成とそ の応用" について検討してきた。それらの中で Ls$\mathrm{CONH}_{2}$ 系テロマーは合成洗剤ビルダーとして, 高硬度 水溶液において硬度の上昇に従い, かえって表面張力は 低下し, 可溶化能は向上し, ビルダーとして優れた性能 を示した ${ }^{2)}$-3)。また Ls-VPr-MA 系テロマーは合成 洗剂へ 3〜 5\% 配合することにより洗浄効率は約 $20 \%$ 向上した。特にセッケンに配合することにより高硬度水

注 1)この報文を特殊型界面活性剂の研究（第17 報）とする。

2）施郝: Bull. Chem. Soc. Jpn., 59, 2963 (1986)
溶液において極めて高い洗浄効率を示し, 特に被洗浄布 がポリエステルの場合, 約 $50 \%$ の向上がみられ, カル シウムセッケン分散剤 (LSDA) として優れた機能を示 しだ)。

合成洗剂ビルダー及び LSDA は，公害的対策上高い 生分解性が要求される。オリゴマー領域にある一連の力 ルボキシラート型ビルダー及びポリ（ $\beta$-リンゴ酸ナト リウム) の生分解性については, 阿部らの詳細な報 告 ${ }^{5}$ ，6) がある。本報告においては上記テロマーの化学 及び生分解性を測定し、テロマーの官能基及びそれらの 組み合わせによる分解性の差異を, テロマーと同一もし くは類似の官能基を有するポリマー及び合成洗剂に使用 
されている界面活性剤及びセッケン成分と比較検討し た。

\section{2 実験}

\section{$2 \cdot 1$ 試 料}

実験に供したテロマー, ポリマー及び界面活性剂を Table-1に示す。テロマーは先に合成したもの2) 文を 用い，ポリマーは和光純薬工業（株）製試薬一級を，ポ リビニルアルコール (PVA) は日本合成化学工業（株） の製品を，また界面活性剂の分枝鎖ドデシルベンゼンス ルホン酸ナトリウム $(\mathrm{ABS})$ とオレイン酸ナトリウム （SOA）は和光純薬工業（株）製試薬一級を直鎖アルキ ルベンゼンスルホン酸ナトリウム (LAS) 及び $\alpha$ ーオレ フィンスルホン酸ナトリウム (AOS) はライオン（株） の寄贈品をそれぞれ用いた。

$2 \cdot 2$ 化学的酸素要求量 $(\mathrm{COD})$, 生化学的酸素要求量 (BOD) 測定法

COD はJS K 0102 の $100^{\circ} \mathrm{C}$ における過マンガン酸 カリウムによる酸素消費量測定法により求め, 試料 $1 \mathrm{~g}$ 当たりの酸素の $\mathrm{mg}$ 数 $(\mathrm{mg} \mathrm{O} / \mathrm{g})$ で表した。なお，化 学的分解速度の測定は, 上記条件にて 0 240 min 加熱 し，その間の $\mathrm{COD}$ 值の変化を測定した。これらの值が 一次反応速度式に適合することを確かめ, 初期及び後期 反応速度定数を算出した。

BOD は JIS K 0102 により, 試料濃度を 1000 ppm とし, 植種液は土袞抽出液を用い, $20^{\circ} \mathrm{C}, 5 \mathrm{~d}$ 静置した とき消費された溶存酸素量を試料 $1 \mathrm{~g}$ 当たりの酸素消費 量 $(\mathrm{mg} \mathrm{O} / \mathrm{g})$ で表した。また, 一部の試料については $25 \mathrm{~d}$ の BOD を測定した。これらの值が一次反応速度 式に適合することを確かめ, 反応速度定数を算出した。

試料が完全に酸化された場合の理論的酸素要求量 (ThOD) を算出し COD との比率 (\%) を化学分解率, BOD との比率 $(\%)$ を生分解率として表示した。

\section{3 結果及び考察}

テロマー, ポリマー及び界面活性剂の COD, BOD, ThOD, 化学分解率, 生分解率及び洗浄効率の結果を Table-2 a b に示す。

テロマー, ポリマー及び界面活性剂の中で COD は, PVA が最も高く 886 1160 mg O/gである。ただ重合 度 800 , けん化度 $48.4 \%$ である試料 PVA 800 H 48.4 の $\mathrm{COD}$ は $196 \mathrm{mg} \mathrm{O} / \mathrm{g}$ で極端に低い。これはアセチル基 が多くヒドロキシル基の少ない PVA は, 極めて分解が 困難であることを示している。ポリマーでは, PVP, PSA がほほ $200 \mathrm{mg} \mathrm{O/g}, \mathrm{PAM}$ がやや低く $48 \mathrm{mg}$ O/ g である。界面活性剤は LAS が最も高く $188 \mathrm{mg} \mathrm{O} / \mathrm{g}$, $\mathrm{ABS}$ が最も低く $92 \mathrm{mg} \mathrm{O} / \mathrm{g}$ である。

BODについては, COD と高い相関性を有している。
本実験に供した試料について $\mathrm{Y}=0.94 \mathrm{X}+100.4$ (Y : $\mathrm{BOD} \mathrm{mg} \mathrm{O} / \mathrm{g}, \mathrm{X}: \mathrm{COD} \mathrm{mg} \mathrm{O} / \mathrm{g}$ ) の回帰式が得られ た。相関係数は 0.70 である。 BODもPVA が最も高 く 679 1320 mg O/g の範囲にあり, COD の場合と同 じように試料 PVA $800 \mathrm{H} 48.4$ は BOD $210 \mathrm{mg} \mathrm{O} / \mathrm{g}$ で極端に低い。これはアセチル基の多い PVA は, 生物 化学的にも分解しにくいことを意味している。次いでテ ロマーは 59 $577 \mathrm{mg} \mathrm{O} / \mathrm{g}$ の範囲で, 構成官能基によ り異なる。ポリマーでは PVP, PSA がほぼ $200 \mathrm{mg} \mathrm{O/}$ $\mathrm{g}, \mathrm{PAM}$ がほぼ $50 \mathrm{mg} \mathrm{O} / \mathrm{g}$ で最も低い。一般界面活性 剤は $122 \sim 856 \mathrm{mg} \mathrm{O} / \mathrm{g}$ の範囲にあり, ABS が最も低く $122 \mathrm{mg} \mathrm{O} / \mathrm{g}$,オレイン酸ナトリウムが最も高く $856 \mathrm{mg}$ $\mathrm{O} / \mathrm{g}$ であり，一般の傾向とよく一致している。

生分解率については, 一般的に PVA が最も高く $70 \%$, 次いでオレイン酸ナトリウム，テロマー, PVA 以外のポリマーの順である。ポリマーでは先に述べたよ うにPVAが最も高く, ついでPAS, PVP の順であり PAM が最も低く $3.8 \%$ である。一般界面活性剂につい てはオレイン酸ナトリウムが最も高く $34.5 \%$, 次いで AOS, LAS の順であり ABS が最も低く $6.6 \%$ である。 生分解率は，直鎖アルキルベンゼンスルホン酸塩が分枝 鎖アルキルベンゼンスルホン酸塩より優れ，またAOS が良好で, 従来の文献值 ${ }^{7)}$ ８) と一致した。

テロマーの生分解率については, Ls-COONa 系が最 も高く $17.6 \sim 49.3 \%$ で，ついでLs-VPr系で $13 \%$ で あり， $\mathrm{Ls}-\mathrm{CONH}_{2}$ 系は 4 9\% で最も低い。これより テロマーについては，カルボキシラート基を有するもの が最も生分解しやすく，次で $\alpha$ ーピロリドン基，カルバ モイル基の順に生分解しやすい。Ls-VPr-MA 系テ ロマーの場合は，官能基として $\alpha$-ピロリドン基の外 に,メトキシカルボニル基が存在する。メトキシカルボ 二ル基の存在は生分解率を高いが，メトキシカル ボニル基の含量が $90 \mathrm{~mol} \%$ を超えたテロマーLs 9.0 VPr $22.2 \mathrm{MA}$ の場合, 生分解率は極端に低下してい る(Table-2 a)。Ls-VPr-MA 系テロマーの加水分 解を行いメトキシカルボニル基をカルボキシル基に变換 した場合，けん化度が $48 \mathrm{~mol} \%$ に至るまでは生分解 率が低下するが， $48 \mathrm{~mol} \%$ を超えるとほとんじ变化し ていない(Fig.-1)。Ls-COONa 系テロマーの生分解 率が高いことより，ナトリウムカルボキシラート基の導 入は生分解率を高兴考えら机るが，逆の傾向を示し ており，これより $\alpha$ 一ピロリドン基単独よりメトキシカ ルボニル基との組み合わせが微生物分解率を高め，その メトキシカルボニル基を加水分解するとその分解率が低 下することがわかった。メトキシカルボニル基がカルボ キシラート基より微生物分解しやすいのか, あるいは $a$ 一ピロリドン基との組み合わせによる相互作用によるも のか明らかでない。 


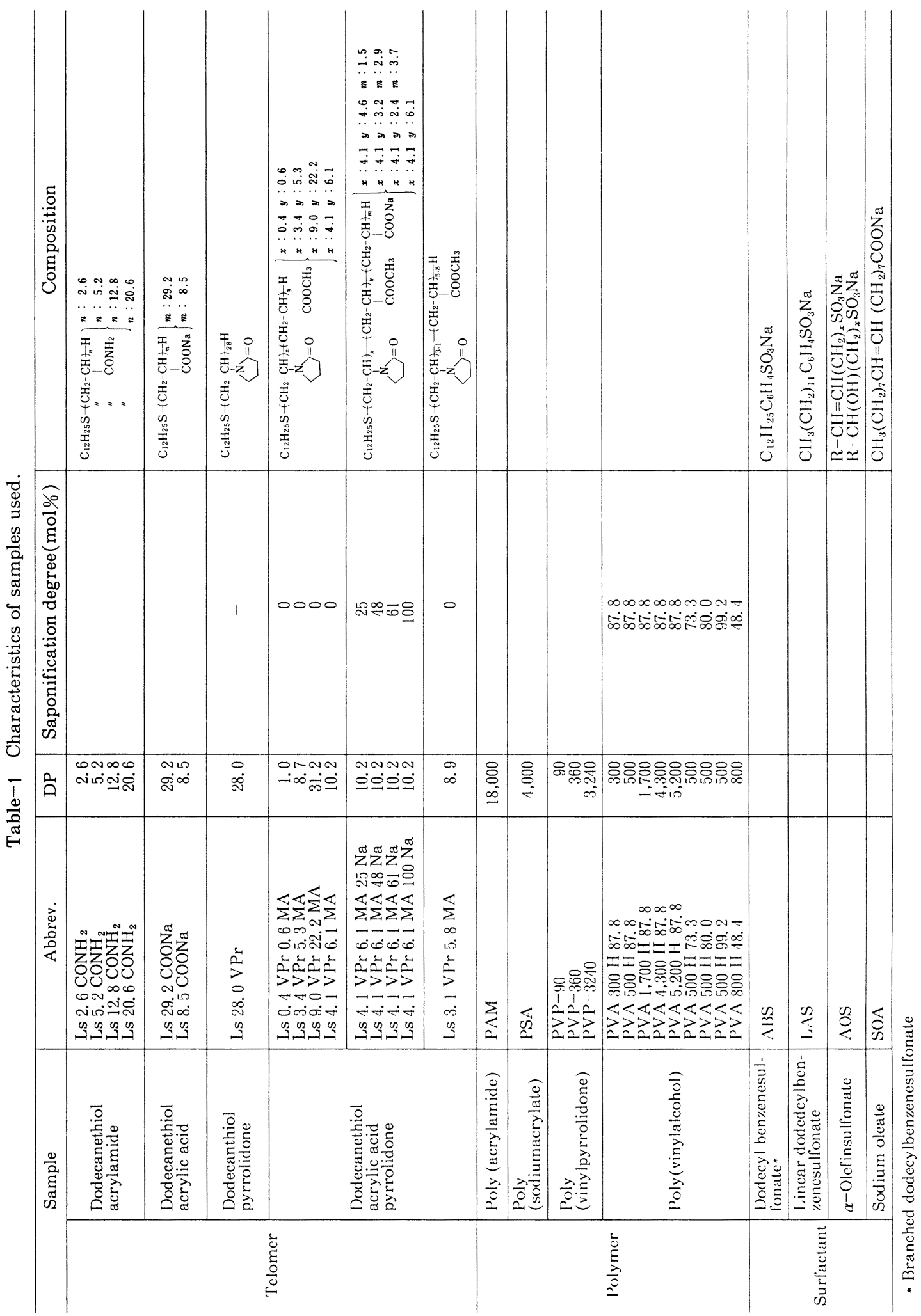


Table-2 a Chemicaloxidability, biodegradability and detergency of telomers.

\begin{tabular}{|c|c|c|c|c|c|c|}
\hline \multirow[b]{2}{*}{ Sample } & \multirow{2}{*}{$\begin{array}{c}\text { ThOD } \\
(\mathrm{mg} \mathrm{O} / \mathrm{g})\end{array}$} & \multicolumn{2}{|c|}{ Chemicaloxidability } & \multicolumn{2}{|c|}{ Boidegradability } & \multirow{2}{*}{$\begin{array}{c}\text { Detergency* } \\
(\%)\end{array}$} \\
\hline & & $\begin{array}{c}\mathrm{COD} \\
(\mathrm{mg} \mathrm{O} / \mathrm{g})\end{array}$ & $\begin{array}{c}\mathrm{COD} / \mathrm{ThOD} \\
(\%)\end{array}$ & $\begin{array}{c}\mathrm{BOD} \\
(\mathrm{mg} \mathrm{O} / \mathrm{g})\end{array}$ & $\begin{array}{c}\mathrm{BOD} / \mathrm{ThOD} \\
(\%)\end{array}$ & \\
\hline $\mathrm{Ls} 2.6 \mathrm{CONH}_{2}$ & 2177 & 204 & 9.4 & 119 & 5.5 & - \\
\hline Ls $5.2 \mathrm{CONH}_{2}$ & 1910 & 184 & 9.6 & 126 & 6.6 & - \\
\hline $\mathrm{Ls} 12.8 \mathrm{CONH}_{2}$ & 1639 & 96 & 5.9 & 59 & 3.6 & 91 \\
\hline Ls 20.6 $\mathrm{CONH}_{2}$ & 1544 & 108 & 7.0 & 52 & 3.4 & 92 \\
\hline Ls $29.2 \mathrm{COONa}$ & 1073 & 276 & 25.7 & 529 & 49.3 & 89 \\
\hline Ls 8. $5 \mathrm{COONa}$ & 1339 & 213 & 15.9 & 235 & 17.6 & 86 \\
\hline Ls 28.0 VPr & 2074 & 218 & 10.5 & 265 & 12.8 & 85 \\
\hline Ls $0.4 \operatorname{VPr} 0.6 \mathrm{MA}$ & 2577 & 229 & 8.9 & 464 & 18.0 & 77 \\
\hline Ls $3.4 \operatorname{VPr} 5.3 \mathrm{MA}$ & 2045 & 242 & 11.8 & 388 & 19.0 & 93 \\
\hline Ls 9.0 VPr 22. $2 \mathrm{MA}$ & 5534 & 49 & 0.9 & 67 & 1.2 & 90 \\
\hline Ls $4.1 \mathrm{VPr} 6.1 \mathrm{MA}$ & 2002 & 212 & 10.6 & 577 & 28.8 & 95 \\
\hline Ls 4.1 VPr 6.1 MA $25 \mathrm{Na}$ & 1739 & 346 & 19.9 & 328 & 18.9 & $97^{* *}$ \\
\hline Ls $4.1 \mathrm{VPr} 6.1 \mathrm{MA} 48 \mathrm{Na}$ & 1645 & 275 & 16.7 & 174 & 10.6 & 95 \\
\hline Ls $4.1 \mathrm{VPr} 6.1 \mathrm{MA} 61 \mathrm{Na}$ & 1594 & 268 & 16.8 & 168 & 10.6 & 95 \\
\hline Ls $4.1 \mathrm{VPr} 6.1 \mathrm{MA} 100 \mathrm{Na}$ & 1651 & 242 & 14.7 & 190 & 11.5 & 88 \\
\hline Ls 3.1 VPr $5.8 \mathrm{MA}$ & 2002 & 188 & 9.4 & 406 & 20.3 & - \\
\hline
\end{tabular}

* Condn. of detergency : Test fabric:cotton, content of detergent soln.: LAS 0.02 wt \%, telomer 0.02 wt $\%$. $\mathrm{Na}_{2} \mathrm{SiO}_{3} 0.05 \mathrm{wt} \%, \mathrm{Na}_{2} \mathrm{CO}_{3} 0.03 \mathrm{wt} \%, \mathrm{Na}_{2} \mathrm{SO}_{4} 0.04 \mathrm{wt} \%$; hardness of used water : $300 \mathrm{CaCO}_{3}$ ppm; liquor ratio $30: 1$; time $10 \mathrm{~min}$; temp. $30^{\circ} \mathrm{C}$; Revolution $120 \mathrm{rpm}$. Reference detergency; blank : $71 \%$, +STPP $87 \%$

** The detergency was $96 \%$, when detergent concentration of $0.005 \%$ telomer, $0.02 \%$ LAS and $0.05 \%$ builder was used to wash artificially soiled polyester test fabric in the Terg-O-Tometer.

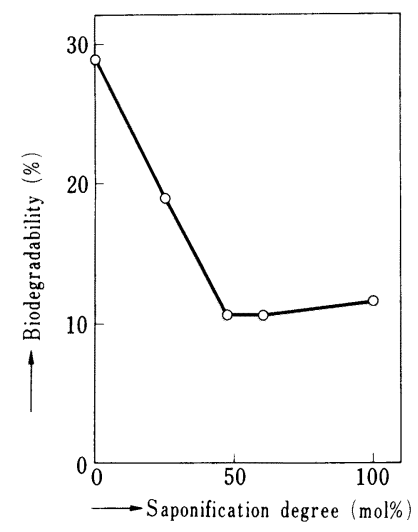

Fig.-1 Relationship between saponification degree and biodegradability of Ls-VPr-MA telomers.

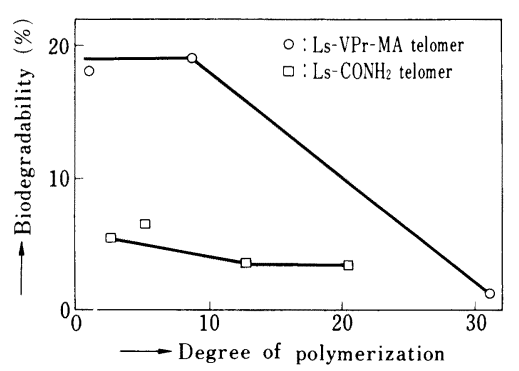

Fig.-2 Relationship between DP and biodegradability of $\mathrm{Ls}-\mathrm{CONH}_{2}-\mathrm{Na}$ and $\mathrm{Ls}-\mathrm{VPr}-$ $\mathrm{MA}-\mathrm{Na}$ telomers. 
Table $-2 \mathrm{~b}$ Chemicaloxidability, biodegradability of polymers and surfactants.

\begin{tabular}{|c|c|c|c|c|c|c|}
\hline \multirow[b]{2}{*}{ Sample } & \multirow{2}{*}{$\begin{array}{l}\text { ThOD } \\
\mathrm{mg} \mathrm{O/g}\end{array}$} & \multicolumn{2}{|c|}{ Chemicaloxidability } & \multicolumn{2}{|c|}{ Biodegradability } & \multirow{2}{*}{$\begin{array}{c}\text { Detergency } \\
(\%)\end{array}$} \\
\hline & & $\begin{array}{c}\mathrm{COD} \\
(\mathrm{mg} \mathrm{O} / \mathrm{g})\end{array}$ & $\begin{array}{c}\mathrm{COD} / \mathrm{ThOD} \\
(\%)\end{array}$ & $\begin{array}{c}\mathrm{BOD} \\
(\mathrm{mg} \mathrm{O} / \mathrm{g})\end{array}$ & $\underset{(\%)}{\mathrm{BOD} / \mathrm{ThOD}}$ & \\
\hline PAM & 1352 & 48 & 3.6 & 51 & 3.8 & 71 \\
\hline PSA & 940 & 227 & 24.2 & 171 & 18.2 & - \\
\hline PVP 90 & 2019 & 229 & 11.3 & 236 & 11.7 & - \\
\hline PVP 360 & 2018 & 203 & 10.1 & 226 & 11.2 & - \\
\hline PVP 3240 & 2018 & 203 & 10.1 & 241 & 11.9 & - \\
\hline PVA 300 H 87.8 & 1788 & 972 & 54.4 & 950 & 53.1 & - \\
\hline PVA $500 \mathrm{H} 87.8$ & 1788 & 960 & 53.7 & 753 & 42.1 & - \\
\hline PVA $1700 \mathrm{H} 87.8$ & 1788 & 1000 & 55.9 & 961 & 53.7 & - \\
\hline PVA 4300 H 87.8 & 1787 & 980 & 54.8 & 1303 & 72.8 & - \\
\hline PVA $5200 \mathrm{H} 87.8$ & 1787 & 900 & 50.3 & 1320 & 73.8 & - \\
\hline PVA 500 H 73.3 & 1759 & 980 & 55.7 & 1032 & 58.7 & - \\
\hline PVA $500 \mathrm{H} 80.0$ & 1771 & 886 & 50.0 & 679 & 38.3 & - \\
\hline PVA 500 H 87.8 & 1788 & 960 & 53.7 & 753 & 42.1 & - \\
\hline PVA 500 H 99.2 & 1817 & 1160 & 63.8 & 955 & 52.6 & - \\
\hline PVA $800 \mathrm{H} 48.4$ & 1721 & 196 & 11.4 & 210 & 12.2 & - \\
\hline $\mathrm{ABS}$ & 2180 & 92 & 4.2 & 122 & 6.6 & - \\
\hline LAS & 2230 & 188 & 8.4 & 400 & 17.9 & - \\
\hline AOS & 2323 & 120 & 5.2 & 582 & 25.1 & - \\
\hline $\mathrm{SOA}$ & 2480 & 172 & 6.9 & 856 & 34.5 & - \\
\hline
\end{tabular}

PVA については, ポリ酢酸ビニルのけん化が進行し, アセチル基が減少し親水基のヒドロキシル基が増加する にしたがい, 重合度 300〜800について考察すると, 生 分解率は上昇している。これはPVA の生物的分解はヒ ドロキシル基より起こることが明らかにされている ${ }^{9)} の$ で，けん化の進行とともに上昇するのであろう。

一般界面活性剂とテロマーとを比較すると, オレイン 酸ナトリウムは Ls-COONa 系テロマーより低く，LsVPr-MA 系テロマーよりやや高い。Ls-VPr-MA 系及びその加水分解テロマーの生分解率は, AOS, LASのそ机に近く, $\mathrm{Ls}-\mathrm{CONH}_{2}$ 系テロマーは ABS に近いかやや低い值を示した。 $\mathrm{Ls}-\mathrm{CONH}_{2}$ 系及び Ls - VPr-MA 系テロマーの重合度と生分解率との関係を

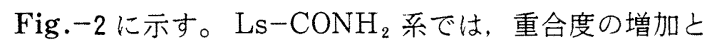
ともに生分解率は低下している。 Ls-VPr-MA 系で は重合度 10 で生分解率 18～28\%, 重合度 30 では 1\%と なり, 重合度の増加とともに急激に低下している。ただ し Ls-VPr-MA 系についてはピロリドン基とメトキ
シカルボニル基の組成も考慮せねばならない。

ポリマーのPVPとPVA についてはFig.ー3 に示す ように, PVP は重合度 $90,300,3200$ の 3 点しか測定し ていないが, 余り重台度の影響はないようである。 PVA はけん化度 $87.8 \mathrm{~mol} \%$ のものについて図示して いるが, 重合度 300 より 500 に至る間はやや低下し, 重 合度 500 を超えると増加の傾向を示している。阿部ら ${ }^{6)}$ はポリ（アクリル酸ナトリウム）及びポリ(メタクリル 酸ナトリウム) の分子量と生分解性との関係において生 分解性の最大值が存在することを指摘している。また常

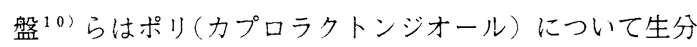
解性を測定し，はじめ生分解性は分子量とともに低下し 最低値を経て上昇する傾向を得ている。これらの現象は, 重合度が大きくなると微生物の菌体内へ自由に透過でき なくなる ${ }^{11}$ が，一方重合度が大きくなると分解反応の 発端となる官能基数も多くなることによると考えられ る。

化学的及び生物学的酸化について反応速度の考察を 
行った。COD は硫酸, 硫酸銀存在下に過マンガン酸カ リウムにより $30 \mathrm{~min}$ 沸腾加熱した時の酸素要求量であ り， BOD は $20^{\circ} \mathrm{C} 5 \mathrm{~d}$ 培養した時の酸素要求量である。 そこで化学的酸化速度については $240 \mathrm{~min}$ 加熱, 生物 学的酸化速度については $25 \mathrm{~d}$ 培養を行い，それぞれに ついて酸化速度の考察を行った。生物学的酸化速度の測 定結果を Fig. -4 に示す。

$\mathrm{COD}$ の加熱時間による $\mathrm{COD}$ 值の変化及び BOD の $25 \mathrm{~d}$ 培養の $\mathrm{BOD}$ 值変化は一次反応式に適合するので, 式 (1)に上り反応速度定数 $k$ を求めた。

$$
k=\frac{1}{t} \ln \frac{D_{\infty}}{D_{\infty}-D_{\imath}}
$$

ここで $D_{\infty}$ は平衡時の $\mathrm{COD}$ 值もしくは BOD 值, $D$ t は加熱 $t \min$ 後の $\mathrm{COD}$ 值もしくは培湌 $t$ 日時の $\mathrm{BOD}$ 值である。なお，化学的酸化においては，反応は全試料 について初期、後期に分かれ, 生物学的酸化においては $\mathrm{SOA}$ のみが初期，後期に分かれる酸化機構を示した。 結果を Table-3に示す。

Table-3 より明らかなように，化学的酸化速度定数

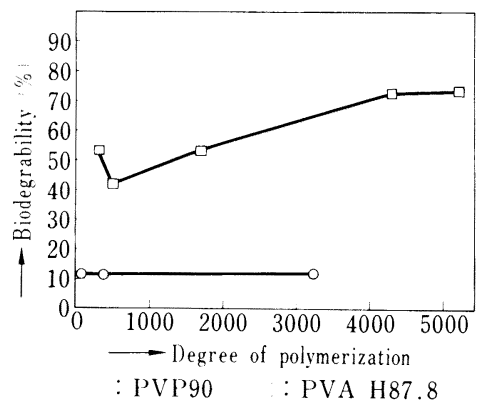

Fig. -3 Relationship between DP and biodegradability of poly(vinyl alcohol)and poly(vinyl pyrrolidone).

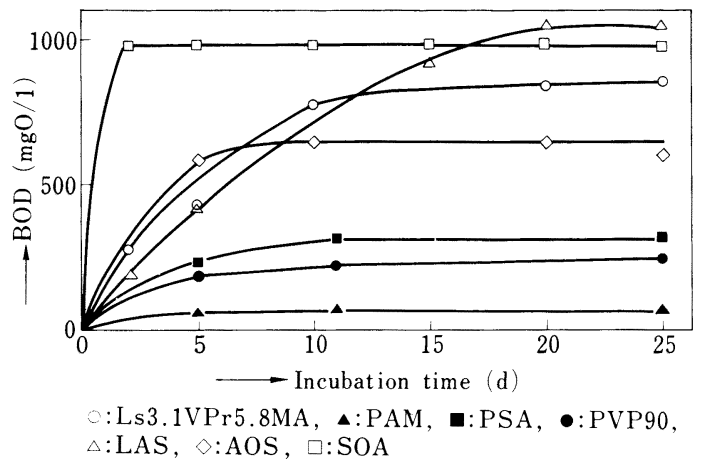

Fig. -4 Change of BOD value in incubation time.

は初期速度定数については AOS が最も大きく, 次いで, LAS, Ls-VPr-MA 系テロマーであり，SOA がやや 小さい。後期速度定数は初期に比し数值が小さく, また 差も小さいが, LAS が最も大きく次いで AOS, Ls 3.1 VPr 5.8 MA 系テロマーであり, SOA が最も小さい。 生物学的酸化反応は SOA のみが初期, 後期に分かれる 機構を示した。生物学的酸化速度定数はSOA が極立っ て大きく次いで PSA, PVP 90, AOS, LAS, Ls 3.1 VPr 5.8 MA, PAM の順であり PAM が最も小さい。 一般的に知られているように SOA が極めて大きい速度 定数を示している。テロマー, 界面活性剤及びポリマー を通じて生物学的酸化速度定数は官能基として，カルボ キシラート基を有するSOA, PSA が大きく，次いでピ ロリドン基を有する PVP, スルホン基を有する AOS， LAS の順であり，カルバモイル基を有するPAM が最 小である。

\section{4 総括}

Table-2 a に示しているように，木綿污染布の洗浄

Table-3 Chemical and biochemical degradation rate constant.

\begin{tabular}{c|c|c}
\hline Sapmle & $\begin{array}{c}\text { Chemical degradation rate constant } \\
\left(\mathrm{h}^{-1}\right)\end{array}$ & $\begin{array}{c}\text { Biochemical degradation rate constant } \\
\left(\mathrm{d}^{-1}\right)\end{array}$ \\
\hline Ls 3.1 VPr 5.8 MA & $K_{1}: 1.61^{*}$ & 0.11 \\
\hline$K_{2}: 0.37^{* *}$ & - & 0.10 \\
PAM & - & 0.21 \\
PSA & - & 0.20 \\
PVP 90 & $K_{1}: 1.61^{*}$ & 0.12 \\
\hline LAS & $K_{2}: 0.55^{* *}$ & 0.18 \\
AOS & $K_{1}: 2.77^{*}$ & $K_{1}: 1.93^{*}$ \\
& $K_{2}: 0.46^{* *}$ & $K_{2}: 0.01^{* *}$ \\
\hline
\end{tabular}

* Initial degradation rate

** Final degradation rate 
において, LAS のみではその洗浄効率 71\%で, それに トリポリリン酸ナトリウム (STPP) を加えた場合でも 87\% であるのに対し, 添加により 90〜 97\%の高い洗浄 効率を示す $\mathrm{Ls}-\mathrm{CONH}_{2}$ 系, $\mathrm{Ls}-\mathrm{COONa}$ 系及び $\mathrm{Ls}-$ VPr-MA 系テロマー型界面活性剂の COD 及び BOD を, 一般水溶性ポリマーである PAM, PSA, PVP 及 びPVA 上，また一般界面活性剤である ABS, LAS， $\mathrm{AOS}$ 及びオレイン酸ナトリウム $(\mathrm{SOA})$ と比較検討し た。 $\mathrm{COD} と \mathrm{BOD}$ と関係については, COD の高い ものは一般に BOD も高い傾向があり, 相関性が認めら れた。水溶性高分子のなかではPVA 系がいずれも極め て高い値を示している。テロマー Ls-VPr-MA 系及 び Ls-COONa 系テロマーのなかには, 他の水溶性高 分子の PVP 系, PSA 上り高く, 一般界面活性剂の SOA, AOS に次ぐ BOD 值を示し，その生分解率では PVA についで SOA や AOS より高い値を示すものが あり,この点からもすぐれたビルダーと考えられる。な お，こ机ら Ls-VPr-MA 系, Ls-COONa 系テロマー 及び PVA の BOD は重合度及びけん化度により大きく

影響されることがわかった。

本研究において実験に協力された中川畺弓氏また試料

\section{国際油脂情報}

[I.N.F.O, Vol 3, No. 11, 1988, 吉富和彦]

\section{ネアメリカーカナダ貿易協定にトラブルか}

カナダとアメリカとの自由貿易協定案は, 1988 年 11 月 21 日のカナダ国会議員選挙におけるおもな論点として クローズアップされている。保守党のマルローニー首相は自由党の本貿易協定締結に反対の立場をとる対抗者 ジョン・ターナー氏に最近票数の地盤を奪われつつある。

ネフランス, ネッスル社の取得を検討へ

フランス政府はその独占委員会が U.K. Rowntree チョコレート・グループをスイスに據点を置くネッスル・ グループによって䛦り受ける提案を検討することになろうと発表した。提案された合併によって，ネッスルはフ ランスのチョコレート市場の $25 \%$ 以上を占有することになる。委員会の報告は, フランス財務省に政府がとる べき措置に関し，財務上の決断を与えることになろう。

ネユニリバー，ダーキー買収に同意

ユニリバー・グループは Durkee Industrial Foods グループを Hanson Industries 社から買収することに 同意した。購入価格は 1 億 8,500 万ドルと報告されている。ダーキーは特殊油脂, 冷凍ベーカリ一製品や製菓用 コーティング剤を生産している。

\section{ネアメリカの新農業法案, ヒアリングを期待}

アメリカ大豆協会の会長は 1990 年アメリカ農業法案に関し，ヒアリングが 1989 年の第 2,4 半期から始まる だろうという。1988 年初期のアメリカ大豆協会の年会において，共和党と民主党の農業政策アドバイザーたち は, 現在の法令改訂は考えていないという。

\section{太国際会議（詳細略）}

OAustralian National Agricultural Outlook Conference ; 1989 年 1 月 17〜19 日，オーストラリアのキャ ンベラにおいて開催

O30 th International Conference on Biochemistry of Lipids ; 1989 年 9 月 26〜29日, イタリーの Stresa (Lake Maggiore) において開催。

OShort Coure on Analysis of Fats, Oils and Lipoproteins ; 1988 年 11 月 26 日〜12月 2 日, アメリカ，イ リノイ州 Rosemont において開催 